\title{
Angiotensin-Converting Enzyme N-Terminal Inactivation Alleviates Bleomycin-Induced Lung
} Injury

Ping Li, ${ }^{*}$ Hong D. Xiao, ${ }^{\dagger}$ Jianguo Xu, ${ }^{\ddagger}$ Frank S. Ong, ${ }^{*}$ Mike Kwon, ${ }^{\dagger}$ Jesse Roman, ${ }^{\S}$ Anthony Gal, ${ }^{\dagger}$ Kenneth E. Bernstein, ${ }^{* \Uparrow}$ and Sebastien Fuchs ${ }^{\star \Uparrow}$

From the Departments of Biomedical Sciences," and Pathology and Laboratory Medicine, "Cedars-Sinai Medical Center, Los Angeles, California; the Departments of Pathology and Laboratory Medicine, ${ }^{\dagger}$ and Pulmonary Medicine, ${ }^{\ddagger}$ Emory University, Atlanta, Georgia; and the Department of Medicine, ${ }^{\S}$ University of Louisville, Louisville, Kentucky

Bleomycin has potent anti-oncogenic properties for several neoplasms, but drug administration is limited by bleomycin-induced lung fibrosis. Inhibition of the renin-angiotensin system has been suggested to decrease bleomycin toxicity, but the efficacy of such strategies remains uncertain and somewhat contradictory. Our hypothesis is that, besides angiotensin II, other substrates of angiotensin-converting enzyme (ACE), such as the tetrapeptide $\mathrm{N}$-acetyl-seryl-aspartyl-lysyl-proline (AcSDKP), play a significant role in controlling fibrosis. We studied bleomycin-induced lung injury in normotensive mice, termed N-KO and $\mathrm{C}-\mathrm{KO}$, which have point mutations inactivating either the $\mathrm{N}$ - or C-terminal catalytic sites of ACE, respectively. N-KO, but not $\mathrm{C}-\mathrm{KO}$ mice, have a marked resistance to bleomycin lung injury as assessed by lung histology and hydroxyproline content. To determine the importance of the ACE N-terminal peptide substrate AcSDKP in the resistance to bleomycin injury, N-KO mice were treated with S-17092, a prolyl-oligopeptidase inhibitor that inhibits the formation of AcSDKP. In response to bleomycin injection, S-17092treated $\mathrm{N}-\mathrm{KO}$ mice developed lung fibrosis similar to wild-type mice. In contrast, the administration of AcSDKP to wild-type mice reduced lung fibrosis due to bleomycin administration. This study shows that the inactivation of the N-terminal catalytic site of ACE significantly reduced bleomycin-induced lung fibrosis and implicates AcSDKP in the mechanism of protection. These data suggest a possible means to in- crease tolerance to bleomycin and to treat fibrosing lung diseases. (Am J Pathol 2010, 177:1113-1121; DOI: 10.2353/ajpath.2010.081127)

Pulmonary fibrosis is a serious medical problem affecting more than 200,000 patients in the United States and is responsible for more than 40,000 deaths annually. At present, few treatments are available to counteract pulmonary fibrosis. Modulation of the renin-angiotensin system has been suggested to alter the evolution of this ailment, but the efficacy of such strategies remains uncertain and the conclusions of previous reports are somewhat contradictory. ${ }^{1-4}$

The renin-angiotensin system controls blood pressure and renal homeostasis in mammals. Angiotensin-converting enzyme (ACE) is the last enzyme of a cascade generating angiotensin II. The complete inactivation of ACE in mice results in a complex phenotype, including low blood pressure, anemia, male sterility, and kidney malformations. ${ }^{5,6}$ These knockout mice, as well as data from several different experimental approaches, demonstrate physiological roles for ACE beyond simple blood pressure control. For example, angiotensin II has been implicated in promotion of fibrosis. ${ }^{7-9}$

Although a single polypeptide chain, ACE is composed of two homologous but independent catalytic domains. These domains, termed the $\mathrm{N}$ - and $\mathrm{C}$-domains, each bind a single zinc atom, which is required for catalysis. ${ }^{10}$ Both domains can cleave angiotensin I, and both domains can degrade bradykinin; however, the two

Supported by National Institutes of Health grants R01-DK039777 and RO-DK051445 and K99-HL088000 (to S.F. and P.L.) and by a beginning grant in aid from the American Heart Association (to S.F. and P.L.). H.D.X. was supported by a scientist development grant from the American Heart Association.

Accepted for publication April 29, 2010.

The authors declare no relevant financial relationships.

Address reprint requests to Sebastien Fuchs, M.D., Ph.D., Department of Biomedical Sciences and Department of Pathology, Cedars-Sinai Medical Center, Davis Bldg., 110 N. George Burns Rd., Los Angeles CA 90048. E-mail: fuchss@cshs.org. 
domains of ACE have some important differences. For example, only the $\mathrm{N}$-domain can use the tetrapeptide $\mathrm{N}$-acetyl-seryl-aspartyl-lysyl-proline (AcSDKP) as a substrate, cleaving this peptide into inactive fragments. ${ }^{11}$ Initially, AcSDKP was presented as a suppressor of bone marrow proliferation. ${ }^{12}$ However, several in vivo studies have challenged this assertion and suggested that AcSDKP may suppress fibrosis in models of tissue injury. ${ }^{13} \mathrm{ACE}$ is the primary enzyme responsible for the degradation of AcSDKP; its actions in producing the profibrotic molecule angiotensin II and in degrading the antifibrotic molecule AcSDKP suggest that ACE and the renin-angiotensin system may be important in some fibrotic diseases.

To further investigate the role of ACE in lung fibrosis, we used bleomycin to induce lung fibrosis in two new strains of genetically engineered mice with point mutations eliminating zinc binding in one of the two catalytic domains of ACE. The absence of zinc catalytically inactivates either the $\mathrm{N}$-domain or the $\mathrm{C}$-domain, and these mice are termed N-KO and C-KO, respectively. ${ }^{14,15} \mathrm{Be}-$ cause we only introduced point mutations into the ACE gene, both lines of mice have normal serum and tissue levels of ACE protein. Because each line preserves catalytic function in one of the two ACE catalytic domains, both lines have serum levels of angiotensin II and blood pressures equivalent to those of wild-type mice. Thus, these mice allow investigation of ACE domain-specific functions independent of any secondary effects of blood pressure changes, a typical bias introduced with either ACE inhibitors (which inhibit both domains of ACE) or the genetic elimination of all ACE expression (use of ACE knockout animals).

Bleomycin-induced lung injury is a well accepted model of lung fibrosis, ${ }^{16}$ which has direct clinical correlates, because the antineoplastic use of bleomycin is limited by its lung toxicity. Meta-analysis suggests that 10 to $50 \%$ of patients treated with bleomycin develop sufficient lung injury to necessitate cessation of treatment. ${ }^{17}$ Of these, 1 to $3 \%$ die of lung injury. ${ }^{18}$ Here, we show that $\mathrm{N}-\mathrm{KO}$ mice are markedly resistant to the toxicity of bleomycin and that the accumulation of the ACE N-terminal peptide substrate AcSDKP ameliorates bleomycin-induced lung fibrosis. These data suggest a means to increase tolerance to bleomycin and perhaps a new approach for treating other fibrosing lung diseases.

\section{Materials and Methods}

\section{Mice}

We generated mice expressing site-inactivated ACE by homologous recombination. N-KO mice express a fulllength ACE protein in which the N-terminal catalytic site was inactivated by mutating the two zinc-binding histidines $\left({ }^{395} \mathrm{H}\right.$ and $\left.{ }^{399} \mathrm{H}\right)$ to lysines. In the $\mathrm{C}-\mathrm{KO}$ strain, ${ }^{993} \mathrm{H}$ and ${ }^{997} \mathrm{H}$, which are responsible for the zinc binding and catalytic activity of the C-terminal enzymatic site, were mutated to lysines. The generation of these two strains of mice was described in detail previously. ${ }^{14,15,19}$ Because both N-KO and C-KO mice are a genetic mix of 129 and C57BL/6 strains, particular attention was given to the renin locus in these mice. Mice of the 129 strain harbor two renin genes (Ren- $1^{d}$ and Ren-2), whereas C57BL/6 have only one gene $\left(\operatorname{Ren}-1^{c}\right)$. Several reports indicate major phenotypic differences associated with this variation. ${ }^{20,21}$ Therefore, we selected our experimental mice to harbor only one renin gene $\left(\operatorname{Ren}-1^{C}\right)$, a model more similar to humans. This was achieved by three backcrosses to the C57BL/6 background. The genotyping of the renin locus was performed by genomic DNA PCR using the primers RenR1 (5'-AGGCACACACCCACATGCAAG-3') and RenF1 (5'-AGTTGAAGTGCAGCCTCCTTG-3'). The PCR products are $127 \mathrm{bp}$ when two renin genes are present (129 strain) and $109 \mathrm{bp}$ when only one gene is present (C57BL/6 strain). We maintain our mouse colony by breeding heterozygous parents. This strategy allows us to use littermates or age-matched wild-type controls in each experiment. Animal procedures were approved by the Emory University Institutional Animal Care and Use Committee and by Cedars-Sinai Medical Center Institutional Animal Care and Use Committee (Institutional Animal Care and Use Committee 2355).

\section{Drug Administration}

Bleomycin was administered under anesthesia by intratracheal instillation as described previously. ${ }^{22} \mathrm{~A}$ small skin incision was made to expose the trachea. A 25gauge needle was inserted directly into the trachea without reaching the bifurcation, and the animals were maintained on the surgical board at a $30^{\circ}$ angle to ensure correct diffusion of the drug or saline to both lungs. For each experiment, a fresh aliquot of lyophilized bleomycin was dissolved in saline and administered into the trachea. The concentration of the solution was adjusted to inject $2 \mu \mathrm{l} / \mathrm{g}$ The skin was then sutured, and the animal was monitored until complete recovery. A dose of $1 \mathrm{mg} /$ $\mathrm{kg}$ was used in $\mathrm{C}-\mathrm{KO}, \mathrm{N}-\mathrm{KO}$, and their matched control animals. This dose induced consistent lung injury with less than $5 \%$ mortality. A smaller dose of $0.5 \mathrm{mg} / \mathrm{kg}$ of bleomycin was used to injure pure C57BL/6 inbred mice, which are more susceptible than our transgenic animals with a mixed genetic background. For the survival experiment, a higher dose of $5 \mathrm{mg} / \mathrm{kg}$ bleomycin was used.

To inhibit the release of AcSDKP from its precursor, thymosin $\beta 4$, we used the prolyl-oligopeptidase inhibitor S-17092. ${ }^{23}$ This drug was a generous gift from Servier (Suresnes, France). It was administrated daily by intraperitoneal injection at a dose of $10 \mathrm{mg} / \mathrm{kg}$ from a freshly prepared solution. S-17092 administration began the day before bleomycin instillation and continued until the animals were sacrificed.

To determine the importance of the increased AcSDKP concentration in N-KO mice, this tetrapeptide was infused in C57BL/6 wild-type mice (stock no. 664, The Jackson Laboratory, Bar Harbor, ME) at the dose of $1.5 \mathrm{mg} / \mathrm{kg} /$ day by osmotic minipumps (Alzet model 2004). The minipumps were implanted subcutaneously between the scapulas following the manufacturer's instructions. The pumps 
were implanted 4 days before the bleomycin administration to give enough time to reach a plateau of AcSDKP concentration.

To prevent the degradation of AcSDKP by ACE in wild-type mice, groups of mice were also treated with the ACE inhibitor lisinopril at the dose of $16 \mathrm{mg} / \mathrm{kg} /$ day. The drug was also administered by osmotic minipumps.

\section{Histology}

Mice were sacrificed 4, 7, and 14 days after bleomycin administration. Under deep anesthesia, the rib cage was opened to expose the lung. A PE50 tube was secured in the trachea, and $10 \%$ buffered formalin was injected under a constant pressure of $22 \mathrm{~cm} \mathrm{H}_{2} \mathrm{O}$. The trachea was then ligatured. The whole lung was carefully collected in one block with the heart and immersed in formalin overnight. The tissue was then dehydrated and paraffin-embedded using standard techniques. Five-micron coronal sections were obtained from the central part of the lung and were stained with either Masson's trichrome or H\&E. For each animal, both right and left lobes of the lung were examined by a pathologist blinded to the genotype of the mice. Fibrosis was scored after Masson's trichrome staining, following the numerical quantification described by Ashcroft et al. ${ }^{24}$ Using a 10X objective, an average of 20 fields per slide covering both lobes of the lung were assessed for severity of interstitial fibrosis independently of inflammation. Each field was allotted a score between 0 (normal lung) and 8 (total fibrosis). The mean of the scores for all fields was taken as the fibrotic score of the section.

Inflammation was scored as described by Sur et al. ${ }^{25}$ An average of 18 fields per slide were examined and allotted a score between 0 and 4 . A score of 0 indicated the absence of inflammation seen after H\&E staining. A score of 1 was assigned when mild inflammation was present, 2 indicated moderate inflammation, 3 indicated marked inflammation, and 4 was given when the inflammation was severe. The mean of the scores for all fields was used as the inflammatory grade.

\section{Hydroxyproline Measurements}

Fourteen days after bleomycin was administered, mice were deeply anesthetized by intraperitoneal administration of a ketamine/xylazine solution. The entire lung was carefully isolated, avoiding the extraparenchymal tissue, and lyophilized overnight. The tissue was hydrolyzed with $1 \mathrm{ml}$ of $6 \mathrm{~N} \mathrm{HCl}$ at $110^{\circ} \mathrm{C}$ for 16 hours. Then $20 \mu$ l of the homogenate was added to $400 \mu \mathrm{l}$ of chloramine T solution (1.4\% chloramine T, $10 \%$ isopropanol, $4 \%$ citric acid, $0.96 \%$ glacial acetic acid, $5.8 \%$ sodium acetate, and $2.7 \%$ sodium hydroxide) and incubated at room temperature for 20 minutes. Next $400 \mu$ l of Ehrlich's solution was added, and the samples were further incubated for 15 minutes at $65^{\circ} \mathrm{C}$. Absorbance was measured at $550 \mathrm{~nm}$. The concentration of hydroxyproline was then calculated by comparison with a standard curve of hydroxyproline generated for each experiment. Results are expressed as the average of duplicate measurements, in $\mu \mathrm{g}$ of hydroxyproline per mg of dry lung.

\section{AcSDKP Measurement}

The tetrapeptide AcSDKP concentration was measured using an enzyme immunoassay kit from ALPCO (Salem, $\mathrm{NH}$ ). AcSDKP was measured in blood and urine samples. Blood was collected from the vena cava in cold heparinized tubes and, after centrifugation, the plasma was precipitated with methanol. After another centrifugation, the supernatant was evaporated to dryness. The residue was reconstituted with enzyme immunoassay buffer before AcSDKP measurements. Spot urine samples were collected and diluted 10 times with enzyme immunoassay. The AcSDKP concentration was then measured following the manufacturer's instructions.

\section{Survival Analysis}

Five mg of bleomycin per $\mathrm{kg}$ b.wt. was injected into the tracheas of 15 wild-type and $15 \mathrm{~N}-\mathrm{KO}$ mice as described above. The time of death was recorded and plotted on a survival diagram.

\section{Statistics}

All results are expressed as mean $\pm \mathrm{SEM}$, with $P<0.05$ considered statistically significant. Two-tailed Student's $t$-test and two-way analysis of variance analysis were used to analyze significance between groups. The MannWhitney test was used to analyze the histological grades in Figure $1 .{ }^{24,25}$ Statistical analysis of survival data was done using Prism software to perform a Kaplan-Meier analysis.

\section{Results}

Our typical protocol is to place saline containing $1 \mathrm{mg} / \mathrm{kg}$ b.wt. bleomycin directly into the trachea. The mice were studied 14 days later. As expected, wild-type animals developed significant lung injury consisting of focal pulmonary inflammation accompanying fibrosis, as indicated by staining with either Masson's trichrome (Figure 1A) or H\&E (Figure 1B). These features were greatly reduced in $\mathrm{N}-\mathrm{KO}$ mice, indicating a marked reduction of the bleomycin-induced lung injury. The histological features of bleomycin-induced lung injury are well described. ${ }^{26}$ Tissue sections of wild-type and N-KO mice were graded independently for the degree of inflammation and the extent of fibrosis by a pathologist who was unaware of the mouse genotypes (Figure 1C). Wild-type mice showed areas of interstitial pneumonitis with infiltration of the interstitium by mononuclear cells. There was also alveolar cell hyperplasia. Focal fibrosis was present and was more severe in subpleural areas. These findings were either not present or markedly reduced in the lungs of $\mathrm{N}-\mathrm{KO}$ mice. Thus, histological analysis indicated that the inactivation of the $\mathrm{N}$-terminal catalytic site of $\mathrm{ACE}$ 
A

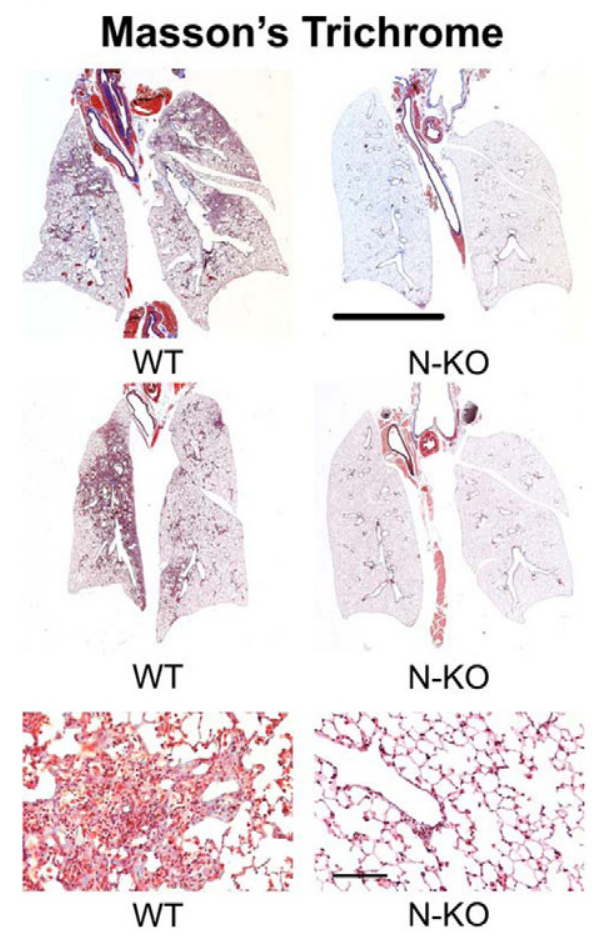

B
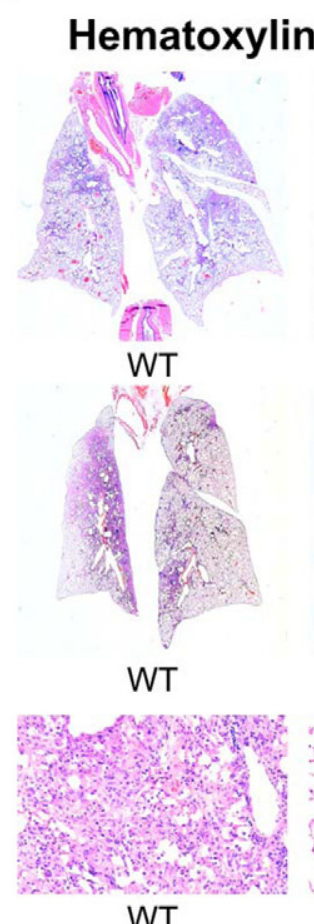

\section{and Eosin}

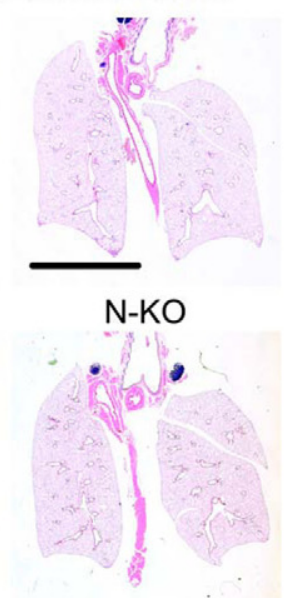

$\mathrm{N}-\mathrm{KO}$

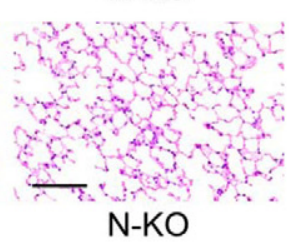

C

\section{Degree of Injury}
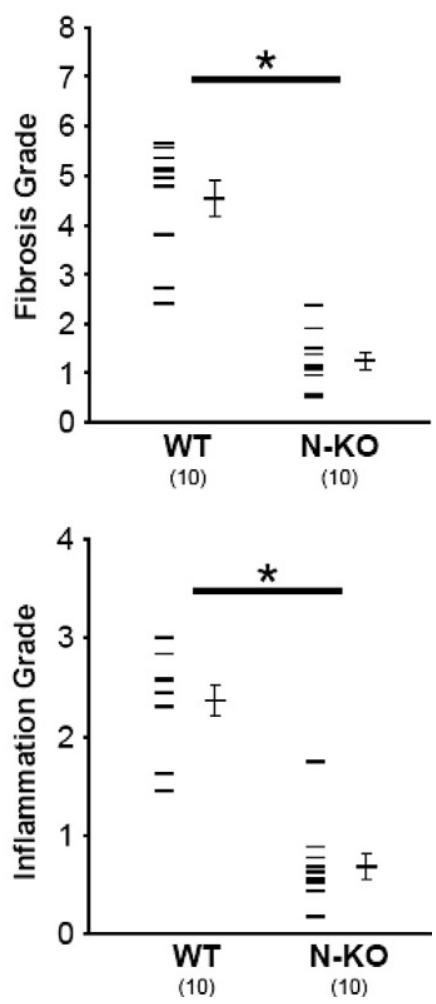

Figure 1. Evaluation of bleomycin-induced lung fibrosis. A and B: Bleomycin-induced lung injury in wild-type (WT) and N-KO mice 14 days after drug administration. Whole lung sections were stained with Masson's trichrome (A) or H\&E (B). These representative sections show focal inflammation and fibrosis in lungs from wild-type mice. In contrast, lungs from N-KO mice show a near-normal appearance. The line represents 5 mm. The lower panels are pictures of lesions taken at a higher magnification (the line is $20 \mu \mathrm{m}$ ). C: Lung histology was graded by a pathologist who was blinded to mouse genotype. Fibrosis was graded using a scale described by Ashcroft et al, ${ }^{24}$ varying from 0 (normal lung) to 8 (total fibrosis). Inflammation was graded using the 0 (normal lung) to 4 (maximum inflammation) scale described by Sur et al. ${ }^{25}$ The inactivation of the N-terminal catalytic site of ACE significantly reduced the lung injury scores for both fibrosis and inflammation $\left(n=10\right.$ per group; $\left.{ }^{*} P<0.001\right)$.

significantly reduced lung injury scores for both inflammation and fibrosis.

To objectively quantify lung injury, we measured the amount of hydroxyproline in the whole lung of $\mathrm{N}-\mathrm{KO}$, wild-type, and, when they became available, C-KO mice. Because both the $\mathrm{N}-\mathrm{KO}$ and $\mathrm{C}-\mathrm{KO}$ strains were on a mixed 129-C57BL/6 genetic background, we used separate littermate wild-type animals from each strain as controls. When treated with saline, the collagen contents of wild-type, $\mathrm{N}-\mathrm{KO}$, and $\mathrm{C}-\mathrm{KO}$ lungs were not significantly different (Figure 2, A and B). Two weeks after intratracheal bleomycin administration, the lung hydroxyproline content of wild-type and $\mathrm{C}-\mathrm{KO}$ mice increased significantly (Figure 2B). In contrast, the pulmonary collagen levels did not change in N-KO mice (Figure 2A). Specifically, the hydroxyproline content of $\mathrm{C}-\mathrm{KO}$ mice increased from $7.16 \pm 0.17 \mu \mathrm{g}$ of hydroxyproline per $\mathrm{mg}$ dry lung weight when the mice were treated with saline to $10.46 \pm 0.56 \mu \mathrm{g} / \mathrm{mg}$ when the mice received bleomycin $(P<0.001)$. This was not significantly different from the collagen content of wild-type mice treated with bleomycin (11.37 $\pm 0.54 \mu \mathrm{g} / \mathrm{mg}$ ). In contrast, the hydroxyproline content of $\mathrm{N}-\mathrm{KO}$ lungs was not significantly changed by bleomycin administration; it was $6.53 \pm 0.16 \mu \mathrm{g}$ of hydroxyproline per mg dry lung weight when the mice were treated with saline and $6.98 \pm 0.34 \mu \mathrm{g} / \mathrm{mg} 14$ days after the mice received the intratracheal injection of bleomycin. This was significantly less than the $10.59 \pm 0.95 \mu \mathrm{g}$ of hydroxyproline per mg dry lung weight measured in control mice treated with bleomycin $(P<0.001$ by analysis of variance). Thus, hydroxyproline measurements corroborate the histological observations presented in Figure 1. These data show that $\mathrm{C}-\mathrm{KO}$ mice mimic the behavior of wild-type mice. In contrast, N-KO mice demonstrate substantial resistance to bleomycin-induced lung fibrosis.

Weight loss is a typical parameter secondary to bleomycin administration and is often associated with the severity of pulmonary injury. ${ }^{27}$ Intratracheal instillation of bleomycin induced a weight loss of $7.2 \pm 2.0 \%$ in wildtype animals and only $0.8 \pm 1.0 \%$ in $\mathrm{N}-\mathrm{KO}$ mice $(P<$ 0.01 ) (Figure 3). In contrast, there was no significant difference in weight loss between C-KO mice and wildtype controls.

AcSDKP is hydrolyzed exclusively by the $\mathrm{N}$-terminal domain of ACE. Thus, not surprisingly, the AcSDKP concentration was increased in the plasma of $\mathrm{N}-\mathrm{KO}$ mice compared with the plasma of either wild-type or $\mathrm{C}-\mathrm{KO}$ mice $(\mathrm{N}-\mathrm{KO}, 2.63 \pm 0.99 \mathrm{nmol} / \mathrm{l} ; \mathrm{C}-\mathrm{KO}, 0.30 \pm 0.06$ $\mathrm{nmol} / \mathrm{l} ; \mathrm{WT}, 0.36 \pm 0.04 \mathrm{nmol} / \mathrm{l} ; n=4$ per group; $P<0.05$ 


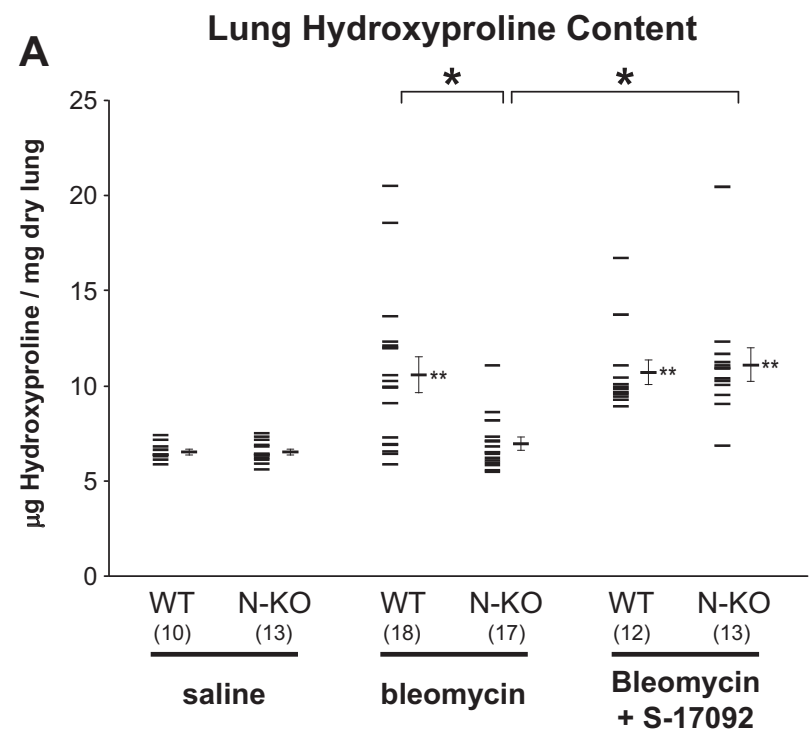

B

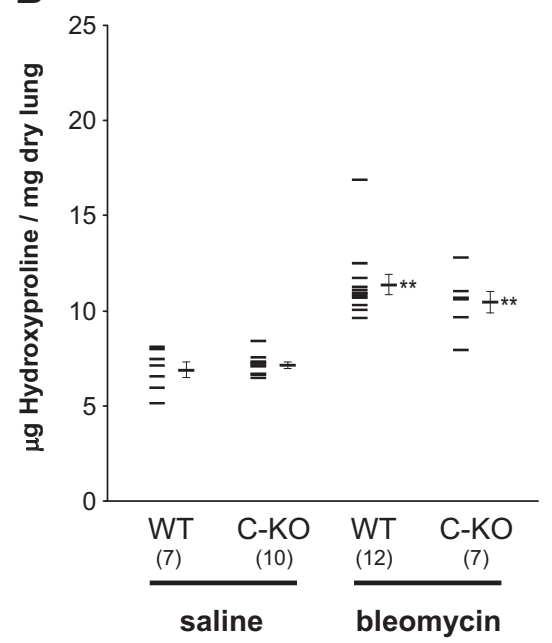

Figure 2. Lung hydroxyproline content. Inactivation of the $\mathrm{N}$-terminal site of ACE prevents collagen deposition in the lung after bleomycin injection. Lung hydroxyproline content was measured in wild-type (WT) and N-KO mice (A) or $\mathrm{C}-\mathrm{KO}$ mice (B) two weeks after intratracheal injection of either saline or bleomycin. Because N-KO and C-KO mice are on a mixed 129-C57BL/6 genetic background, appropriate littermate wild-type mice were used for each strain. N-KO and wild-type littermates were also treated with a combination of bleomycin and S-17092, a prolyl-oligopeptidase inhibitor, to reduce the production of AcSDKP. Data points for individual mice are shown, as well as the group means \pm SEM. The number of animals per group is indicated in parentheses. ${ }^{*} P<0.01 ;{ }^{* *} P<0.01$ when a group is compared with the saline-treated group of the same genotype (ie, N-KO mice treated with bleomycin/S-17092 versus N-KO mice treated with saline alone). The inactivation of the N-terminal catalytic site of ACE in N-KO mice prevents bleomycin-induced lung collagen deposition. Inhibition of prolyl-oligopeptidase with S-17092 increases bleomycin-induced lung collagen in $\mathrm{N}-\mathrm{KO}$ mice.

comparing $\mathrm{N}-\mathrm{KO}$ with either wild-type or $\mathrm{C}-\mathrm{KO}$ ). Because the concentration of AcSDKP in the urine directly reflects peptide levels in the plasma, we used urine measurements to estimate AcSDKP metabolism in our mice. ${ }^{28,29}$ In addition, measurement of AcSDKP in the urine is technically easier, and urine collection does not require the sacrifice of the animals. AcSDKP concentrations were significantly increased in the urine of the $\mathrm{N}-\mathrm{KO}$ mice compared with those in wild-type animals, $176.2 \pm 8.8$

\section{Bleomycin-Induced Weight Loss}

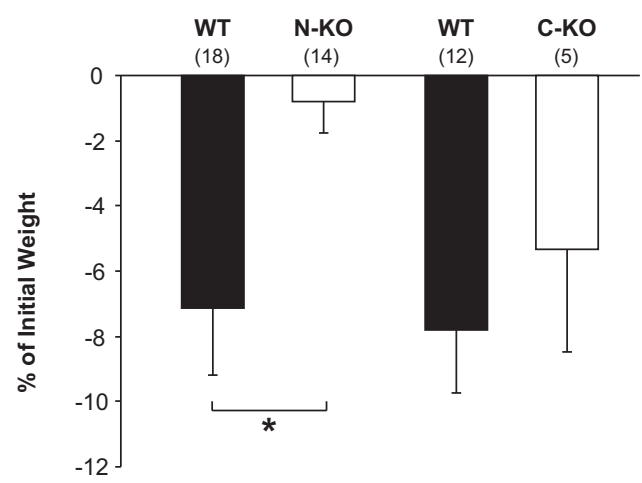

Figure 3. Bleomycin-induced weight loss. Inactivation of the N-terminal site of ACE prevents weight loss after bleomycin injection. Mice were weighed just before intratracheal bleomycin infusion and two weeks later, at sacrifice. The difference in weight is reported as a percentage of the initial weight. $\mathrm{N}-\mathrm{KO}$ mice lost significantly less weight than either wild-type or C-KO mice. The number of animals per group is indicated in parentheses. Values are means \pm SEM $^{*} P<0.01$

versus $45.1 \pm 5.8 \mathrm{nmol} / \mathrm{l}$, respectively $(P<0.001)$ (Figure 4). In comparison, AcSDKP concentration in C-KO urine was only slightly reduced to $24.9 \pm 5.2 \mathrm{nmol} / \mathrm{l}$ compared with that in wild-type urine $(P=0.25$ by analysis of variance). The tetrapeptide AcSDKP is released from its precursor thymosin- $\beta 4$ by the serine peptidase prolyl oligopeptidase. ${ }^{23}$ To determine the importance

\section{AcSDKP Measurements in Urine}

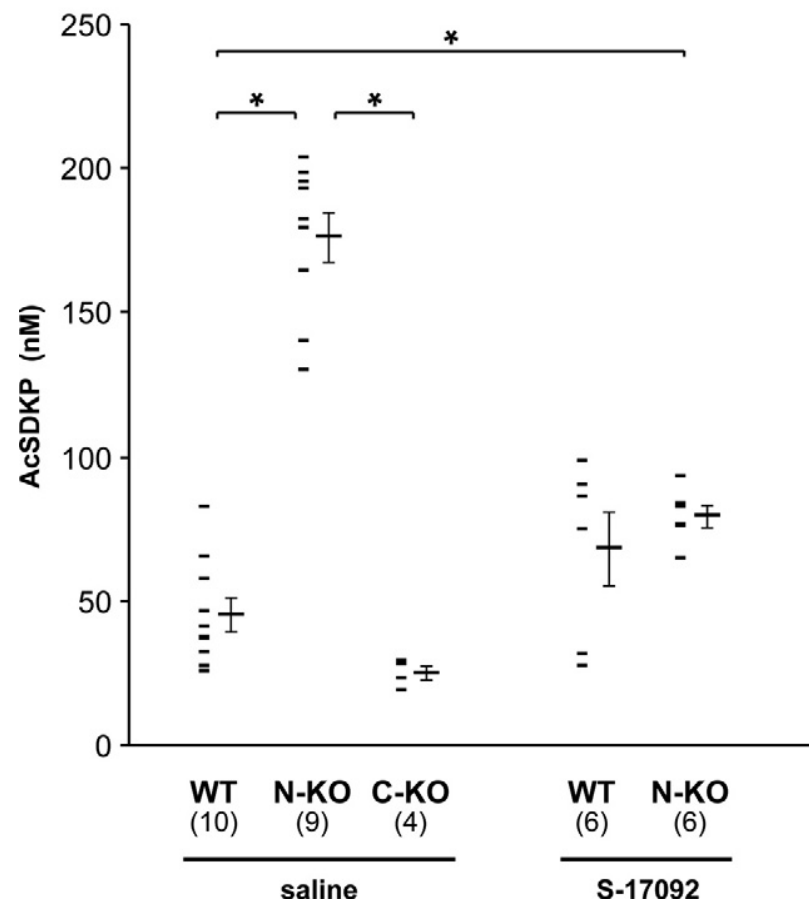

Figure 4. Measurements of AcSDKP in spot urine samples collected from wild-type (WT), N-KO, and C-KO mice. The AcSDKP concentration was measured in the urine of $\mathrm{N}-\mathrm{KO}, \mathrm{C}-\mathrm{KO}$, and wild-type mice treated with saline and in wild-type and $\mathrm{N}-\mathrm{KO}$ mice treated with the prolyl-oligopeptidase inhibitor S-17092. Data points for individual mice are shown, as well as the group means \pm SEM. ${ }^{*} P<0.001$. The number of animals per group is in parentheses. 


\section{Effect of AcSDKP Increase in Wild-Type Mice}

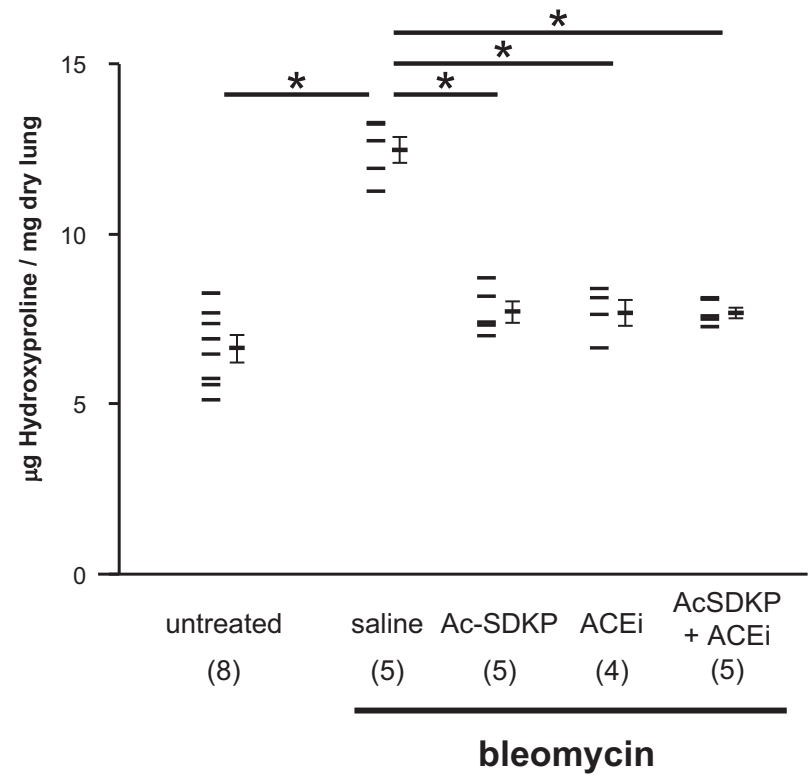

Figure 5. Effect of AcSDKP increases in wild-type mice. Administration of AcSDKP or an ACE inhibitor prevents bleomycin-induced lung fibrosis in C57BL/6 wild-type mice. Whole lung hydroxyproline content was measured in C57BL/ 6 wild-type animals and two weeks after intratracheal instillation of bleomycin. Some mice also received AcSDKP, the ACE inhibitor lisinopril, or a combination of AcSDKP and lisinopril by osmotic minipump. Individual mouse measurements are shown, as well as the group means \pm SEM. The number of animals per group is indicated in parentheses. AcSDKP and/or the ACE inhibitor significantly reduced lung collagen content. ${ }^{*} P<0.001$

of AcSDKP in the mechanism of resistance to bleomycin injury, we inhibited the generation of this peptide with S-17092, a prolyl oligopeptidase inhibitor. In our study, S-17092 was administered by daily intraperitoneal injection starting 1 day before the intratracheal instillation of bleomycin until the sacrifice of the mice. This protocol successfully decreased AcSDKP urine concentration in $\mathrm{N}-\mathrm{KO}$ mice to $79.5 \pm 3.9 \mathrm{nmol} / \mathrm{l}$, which was not different from the $68.1 \pm 12.7 \mathrm{nmol} / \mathrm{l}$ measured in similarly treated wild-type control animals (Figure 4). Under these conditions, N-KO mice were susceptible to bleomycin-induced fibrosis, as indicated by the increased pulmonary hydroxyproline concentration (Figure 2A). The lung hydroxyproline content of N-KO mice treated with bleomycin and S-17092 was $11.12 \pm 0.87 \mu \mathrm{g} / \mathrm{mg}$. This amount was not statistically different from the hydroxyproline concentration of $10.71 \pm 0.65 \mu \mathrm{g} / \mathrm{mg}$ measured in lungs from wild-type mice treated in an identical fashion.

The above data suggest that protection against bleomycin-induced lung injury is substantially dependent on the increased levels of AcSDKP present in N-KO mice. If this hypothesis is true, then the delivery of exogenous AcSDKP should have a protective effect, even in wildtype mice. To test this, AcSDKP was administered to wild-type mice at a rate of $1.5 \mathrm{mg} / \mathrm{kg} /$ day by osmotic minipump. Four days after minipump placement, intratracheal bleomycin was administered, and 2 weeks later, lungs were collected. As seen in Figure 5, treatment of mice with AcSDKP substantially reduced lung hydroxyproline content compared with that of mice treated with a

\section{AcSDKP Measurements in Urine}

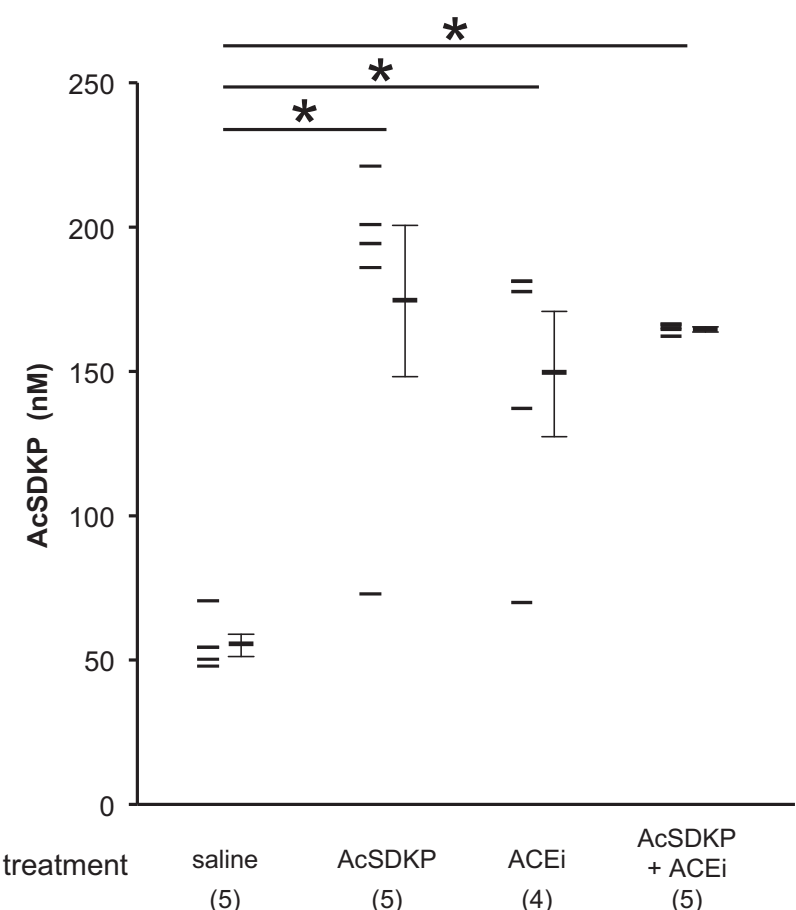

Figure 6. Measurements of AcSDKP in spot urine samples collected from C57BL/6 wild-type mice implanted with osmotic minipumps. Wild-type $\mathrm{C} 57 \mathrm{BL} / 6$ mice were implanted with an osmotic minipump to deliver either saline, AcSDKP, the ACE inhibitor lisinopril, or a combination of AcSDKP and lisinopril. The AcSDKP concentration was measured in a spot urine sample The value measured for each animal is shown, as well as the group means \pm SEM. The number of animals per group is indicated in parentheses. ${ }^{*} P<0.01$.

saline-filled minipump: $7.70 \pm 0.31 \mu \mathrm{g} / \mathrm{mg}$ compared with $12.47 \pm 0.39 \mu \mathrm{g} / \mathrm{mg}$, respectively $\left(P<10^{-4}\right)$. Interestingly, the administration of lisinopril also significantly reduced the lung collagen content of bleomycin-treated mice such that the hydroxyproline levels $(7.68 \pm 0.39$ $\mu \mathrm{g} / \mathrm{mg}$ ) were not significantly different from those of mice treated with AcSDKP. In fact, the amount of lung hydroxyproline in mice treated with either AcSDKP or lisinopril was very close to the measured lung hydroxyproline levels in control mice not treated with bleomycin (6.63 \pm $0.39 \mu \mathrm{g} / \mathrm{mg}$ ). Therefore, it is not surprising that the combination of AcSDKP and lisinopril did not further reduce the collagen content of the lung (Figure 5). In each group, we measured the concentration of AcSDKP in the urine to confirm our ability to modulate peptide concentration in vivo (Figure 6). In the mice treated with AcSDKP urinary AcSDKP increased by approximately threefold so that now the concentration of this peptide was very similar to that measured in N-KO mice (Figures 4 and 6).

Until now, our studies examined the effect of bleomycin 14 days after drug administration. To establish the time course for bleomycin-mediated injury, the lungs of wild-type, $\mathrm{N}-\mathrm{KO}$, and $\mathrm{C}-\mathrm{KO}$ mice were histologically examined $0,4,7$, and 14 days after bleomycin administration. In the absence of the drug or when mice were administered saline instead of bleomycin, there were no differences between the three groups (Figure 7). However, 4 days after bleomycin administration, both wild- 


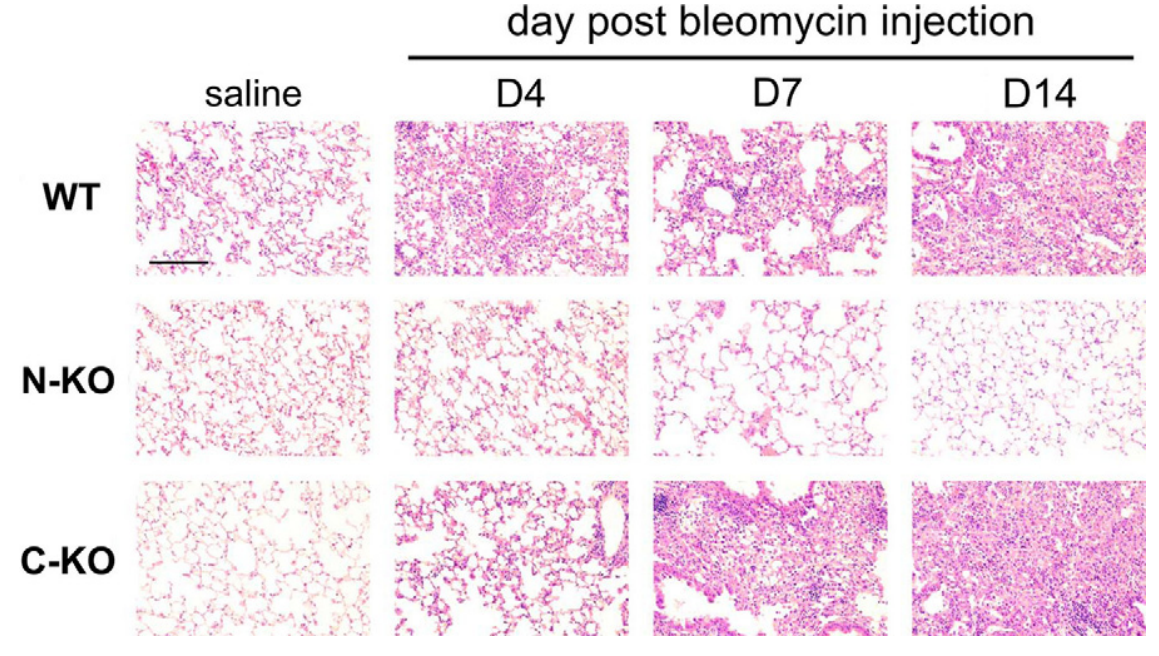

Figure 7. Time-course of bleomycin-induced lung injury. H\&E-stained sections of lungs from wild-type (WT), N-KO, and C-KO mice are shown after either saline injection or 4,7 , and 14 days after bleomycin injection. In the absence of bleomycin, no pathology was observed and the histology of the three groups of mice was similar. However, starting four days after intratracheal bleomycin, the wild-type and C-KO mice showed acute pneumonitis with alveolar damage, which progressed to focal consolidation and focal fibrosis typical of bleomycininduced lung injury. In contrast, lungs from $\mathrm{N}-\mathrm{KO}$ mice showed much less inflammation, fibrosis, and injury at all time points. The line represents $25 \mu \mathrm{m}$. type and C-KO mice showed similar injury, composed of focal pneumonitis that was more prominent in subpleural areas. There were areas of acute alveolitis with alveolar damage and hyaline membranes. By day 7 , there was remodeling of the lung in wild-type and $\mathrm{C}-\mathrm{KO}$ mice with focal alveolar collapse and the formation of cystic airspaces. At this time, early collagen stripes were seen with the Masson's trichrome stain. The consolidation of the lung parenchyma was even more intense 14 days after bleomycin instillation. However, a very different histological picture was observed in N-KO mice (Figure 7). Four days after bleomycin instillation, N-KO mice had far less pneumonitis than that seen in wild-type or C-KO mice. Fibrosis was nearly completely absent 7 days after bleomycin injection. By 14 days, the histological appearance of the lungs was near normal.

Intratracheal injection of our standard dose of bleomycin (1 mg/kg b.wt.) resulted in virtually no deaths of either wild-type or N-KO mice. However, a higher dose of bleomycin (5 mg/kg b.wt.) killed nearly all wild-type mice, with only 1 of 15 wild-type mice surviving 12 days after drug administration (Figure 8). When challenged with the same dose of bleomycin, N-KO mice showed reduced mortality, with 11 of 15 mice surviving 12 days. Ultimately, 4 of $15 \mathrm{~N}-\mathrm{KO}$ mice survived $(P<0.01$ by Kaplan-Meyer analysis).

\section{Survival to High Dose of Bleomycin}

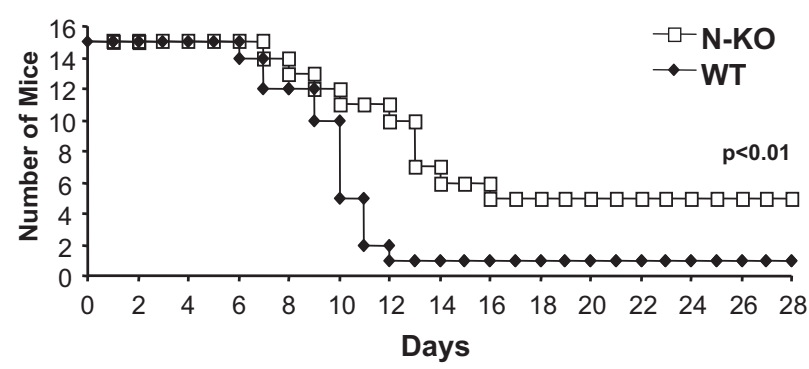

Figure 8. Survival after a high dose of bleomycin. Kaplan-Mayer-type survival analysis of wild-type mice (WT) and N-KO mice treated with 5 $\mathrm{mg} / \mathrm{kg}$ of bleomycin. N-KO mice have a significantly better survival than wild-type littermate mice ( $n=15$ for each group; $P<0.01$ ).

\section{Discussion}

In wild-type mice, intratracheal injection of bleomycin is a common model of pulmonary fibrosis, in which an early inflammatory response is followed by fibroblast activation and collagen deposition. ${ }^{17}$ Previous studies have examined the modulation of the renin-angiotensin system as one approach to diminish the fibrotic process. The efficacy of such strategies is unclear and even somewhat contradictory. For instance, some studies reported beneficial effects of angiotensin $A_{1}$ receptor blockers to alleviate bleomycin-induced lung injury, whereas other studies failed to confirm these observations. ${ }^{1,30}$ On the other hand, ACE inhibitors protect mice treated with bleomycin from lung injury and pulmonary hypertension. ${ }^{4}$ These observations support the hypothesis that another peptide, besides angiotensin II, may play an important role; our studies suggest that AcSDKP may be such a peptide.

AcSDKP was first characterized as a specific substrate of ACE in 1995. ${ }^{11}$ Since then, several studies have demonstrated that this peptide may have antifibrotic properties. For example, the administration of AcSDKP in rats prevents, and even reverses, collagen deposition in a model of myocardial infarction. ${ }^{31}$ In addition, AcSDKP suppresses the proliferation of renal fibroblasts in diabetic $d b / d b$ mice. ${ }^{32}$ In both humans and mice, pharmacological inhibition of ACE increases plasma AcSDKP concentrations by fivefold. ${ }^{33}$ The same five- to sevenfold increase in AcSDKP concentration is observed in ACEnull and $\mathrm{N}-\mathrm{KO}$ mice. ${ }^{14}$ In contrast to angiotensin I or bradykinin, AcSDKP is a substrate of only the $\mathrm{N}$-terminal ACE catalytic site. ${ }^{11}$ Therefore, our hypothesis was that the inactivation of the $\mathrm{N}$-terminal site of ACE may reduce bleomycin-induced lung injury by increasing AcSDKP concentrations.

To test this, we used a mouse model, referred to here as $\mathrm{N}-\mathrm{KO}$, that was created by homologous recombination. ${ }^{14}$ These mice were previously termed ACE 7/7 in our original description. They express a full-length ACE protein with the $\mathrm{N}$-domain selectively inactivated by point mutations impairing its zinc-binding ability. We also used 
mice called C-KO in which the C-terminal catalytic site was inactivated following a similar strategy. ${ }^{15}$ In both lines of mice, ACE protein expression is under the normal native promoter, and, therefore, there is a normal tissue and cellular distribution of the protein. ${ }^{14,15}$

It is worth emphasizing that the nonmutated catalytic sites of ACE in both $\mathrm{N}-\mathrm{KO}$ and $\mathrm{C}-\mathrm{KO}$ mice are fully active. Therefore, these mice are capable of converting angiotensin I to angiotensin II and, at steady state, have normal blood pressure, normal kidney function, and normal hematocrit, parameters that are distinctly abnormal in ACEnull mice. ${ }^{5,6}$ Thus, in contrast with virtually all other animal models, any differences noted between N-KO, C-KO, and wild-type mice are almost certainly independent of the significant blood pressure reduction seen when pharmacological inhibitors of either ACE or the angiotensin AT1 receptor are used.

Our results demonstrate that the inactivation of the $\mathrm{N}$-terminal site of ACE protects N-KO mice against bleomycin-induced lung injury and fibrosis. These mice develop substantially less pulmonary inflammation and collagen deposition, compared with either C-KO or wild-type mice. Furthermore, these mice show enhanced survival when exposed to a dose of bleomycin lethal to wild-type mice. As discussed above, N-KO mice produce angiotensin II from the C terminus of ACE. This is the physiologically dominant site of angiotensin II production by wild-type mice, and thus it is not surprising that the plasma concentration of angiotensin II in N-KO mice is identical to that in wild-type mice. ${ }^{15}$ Thus, these data strongly suggest that changes in angiotensin II do not explain the phenotype of the $\mathrm{N}-\mathrm{KO}$ mice.

To determine the importance of AcSDKP in the protection of $\mathrm{N}-\mathrm{KO}$ mice to bleomycin, we treated these mice with S-17092. S-17092 is a highly specific inhibitor of the prolyl oligopeptidase. ${ }^{34}$ Cavasin et $a{ }^{35}$ reported that this inhibitor did not modify the concentration of other peptides, including angiotensin II, substance $\mathrm{P}$, and $\mathrm{Arg}^{8}$ vasopressin in rat heart, kidney, and brain. Therefore, S-17092 was used to selectively reduce the AcSDKP concentration by inhibiting prolyl-oligopeptidase..$^{23,35}$ With such treatment, the AcSDKP concentration is lowered in N-KO mice and is indistinguishable from that of wild-type animals. Now, N-KO mice are equivalent to wild-type animals in their susceptibility to bleomycin-induced lung fibrosis.

To further demonstrate the central role of AcSDKP in protecting $\mathrm{N}-\mathrm{KO}$ mice against bleomycin, we raised the AcSDKP concentration in wild-type C57BL/6 mice. This experiment showed that increasing the concentration of AcSDKP protects wild-type mice from the fibrosis induced by bleomycin.

One caveat of our studies is that we did not succeed in measuring the AcSDKP peptide concentrations in lung tissue, despite repeated attempts. Our peptide assays showed a high background that obscured proper interpretation of the results. Previous work by Carretero and colleagues $^{35}$ showed that the relative concentrations of AcSDKP in plasma and urine reflected its concentration in heart, brain, and kidney. ${ }^{35}$ The lung has the highest tissue level of ACE expression of any organ. ${ }^{14,15}$ In N-KO mice, all ACE protein, including that in lung, lacks Nterminal catalytic activity and therefore the ability to degrade AcSDKP. Thus, it seems very likely that N-KO mice will show elevated lung levels of AcSDKP, consistent with the elevated levels found in blood and urine. However, this assumption remains to be formally proven.

In conclusion, our work indicates a crucial contribution of the N-terminal catalytic domain of ACE to the development of bleomycin-induced pulmonary fibrosis. The inactivation of the C-terminal catalytic domain of ACE shows no such effect and C-KO animals are as susceptible to bleomycin-induced lung injury as wild-type mice. These observations, along with our previous measures of angiotensin II concentrations in these mice, suggest that another substrate of ACE, specific to the N-domain, may be involved. The hypothesis that AcSDKP prevents the development of fibrosis in response to bleomycin is strongly supported by the observations that i) the tetrapeptide concentration is specifically increased in N-KO mice compared with that in wild-type and C-KO mice, ii) the decrease of AcSDKP in N-KO mice using the prolyloligopeptidase inhibitor S-17092 renders mice susceptible to lung fibrosis, and iii) infusion of AcSDKP protects wild-type mice from bleomycin injury.

Published work by Zhuo et $\mathrm{al}^{36}$ demonstrated a cellspecific binding site for AcSDKP. ${ }^{36}$ One may hypothesize that the effects of AcSDKP are directly due to intracellular events triggered by specific binding of the peptide. Although the intracellular actions of AcSDKP are not well characterized, some studies have suggested an effect on the transforming growth factor- $\beta$ signaling pathway. ${ }^{37}$ Whether this or other cellular pathways are implicated remains to be determined. However, the identification of ACE and AcSDKP as having a major effect on bleomycininduced lung fibrosis suggests new approaches to reduce the progression of pulmonary fibrosis in response to bleomycin and perhaps to a variety of other pathological processes. Thus, it will be important to see whether the manipulation of AcSDKP and/or ACE will modulate the progression of idiopathic pulmonary fibrosis and other fibrosing diseases, because until now medicine has had little to offer patients with these diseases.

\section{Acknowledgments}

We thank Dr. Philippe Morain (Institut de Recherche Servier, Suresnes, France) for his generous gift of the prolyloligopeptidase inhibitor, S-17092. We thank Alberto M. Marchevsky, M.D. (Cedars-Sinai Medical Center) for his assistance in reviewing histological slides. We also thank Jonathan Adams and Ellen Bernstein for technical assistance in maintaining our mice colony and genotyping. The preparation of the histological slides was done by Dieu-Trang Fuchs.

\section{References}

1. Keogh KA, Standing J, Kane GC, Terzic A, Limper AH: Angiotensin II antagonism fails to ameliorate bleomycin-induced pulmonary fibrosis in mice, Eur Respir J 2005, 25:708-714 
2. Otsuka M, Takahashi H, Shiratori M, Chiba H, Abe S: Reduction of bleomycin induced lung fibrosis by candesartan cilexetil, an angiotensin II type 1 receptor antagonist. Thorax 2004, 59:31-38

3. Waseda $Y$, Yasui M, Nishizawa $Y$, Inuzuka K, Takato H, Ichikawa $Y$, Tagami A, Fujimura M, Nakao S: Angiotensin II type 2 receptor antagonist reduces bleomycin-induced pulmonary fibrosis in mice. Respir Res 2008, 9:43

4. Ortiz LA, Champion HC, Lasky JA, Gambelli F, Gozal E, Hoyle GW, Beasley MB, Hyman AL, Friedman M, Kadowitz PJ: Enalapril protects mice from pulmonary hypertension by inhibiting TNF-mediated activation of NF- $\kappa$ B and AP-1. Am J Physiol Lung Cell Mol Physiol 2002, 282:L1209-L1221

5. Krege JH, John SW, Langenbach LL, Hodgin JB, Hagaman JR, Bachman ES, Jennette JC, O'Brien DA, Smithies O: Male-female differences in fertility and blood pressure in ACE-deficient mice. Nature 1995, 375:146-148

6. Esther CR Jr, Howard TE, Marino EM, Goddard JM, Capecchi MR, Bernstein KE: Mice lacking angiotensin-converting enzyme have low blood pressure, renal pathology, and reduced male fertility. Lab Invest 1996, 74:953-965

7. Wang R, Zagariya A, Ang E, Ibarra-Sunga O, Uhal BD: Fas-induced apoptosis of alveolar epithelial cells requires ANG II generation and receptor interaction. Am J Physiol 1999, 277:L1245-L1250

8. Marshall RP, Gohlke P, Chambers RC, Howell DC, Bottoms SE, Unger T, McAnulty RJ, Laurent GJ: Angiotensin II and the fibroproliferative response to acute lung injury. Am J Physiol Lung Cell Mol Physiol 2004, 286:L156-L164

9. Wynn TA: Cellular and molecular mechanisms of fibrosis. J Pathol 2008, 214:199-210

10. Wei L, Alhenc-Gelas F, Corvol P, Clauser E: The two homologous domains of human angiotensin l-converting enzyme are both catalytically active. J Biol Chem 1991, 266:9002-9008

11. Rousseau A, Michaud A, Chauvet MT, Lenfant M, Corvol P: The hemoregulatory peptide $\mathrm{N}$-acetyl-Ser-Asp-Lys-Pro is a natural and specific substrate of the $\mathrm{N}$-terminal active site of human angiotensinconverting enzyme. J Biol Chem 1995, 270:3656-3661

12. Bonnet D, Cesaire R, Lemoine F, Aoudjhane M, Najman A, Guigon M: The tetrapeptide AcSDKP, an inhibitor of the cell-cycle status for normal human hematopoietic progenitors, has no effect on leukemic cells. Exp Hematol 1992, 20:251-255

13. Rasoul S, Carretero OA, Peng H, Cavasin MA, Zhuo J, SanchezMendoza A, Brigstock DR, Rhaleb NE: Antifibrotic effect of Ac-SDKP and angiotensin-converting enzyme inhibition in hypertension. $\mathrm{J} \mathrm{Hy}$ pertens 2004, 22:593-603

14. Fuchs S, Xiao HD, Cole JM, Adams JW, Frenzel K, Michaud A, Zhao H, Keshelava G, Capecchi MR, Corvol P, Bernstein KE: Role of the $\mathrm{N}$-terminal catalytic domain of angiotensin-converting enzyme investigated by targeted inactivation in mice. J Biol Chem 2004, 279: 15946-15953

15. Fuchs S, Xiao HD, Hubert C, Michaud A, Campbell DJ, Adams JW, Capecchi MR, Corvol P, Bernstein KE: Angiotensin-converting enzyme C-terminal catalytic domain is the main site of angiotensin I cleavage in vivo. Hypertension 2008, 51:267-274

16. Adamson IY, Bowden DH: The pathogenesis of bleomycin-induced pulmonary fibrosis in mice. Am J Pathol 1974, 77:185-197

17. Moore BB, Hogaboam CM: Murine models of pulmonary fibrosis. Am J Physiol Lung Cell Mol Physiol 2008, 294:L152-L160

18. Chen J, Stubbe J: Bleomycins: towards better therapeutics. Nat Rev Cancer 2005, 5:102-112

19. Fuchs S, Frenzel K, Hubert C, Lyng R, Muller L, Michaud A, Xiao HD, Adams JW, Capecchi MR, Corvol P, Shur BD, Bernstein KE: Male fertility is dependent on dipeptidase activity of testis ACE. Nat Med 2005, 11:1140-1142

20. Wang Q, Hummler E, Nussberger J, Clement S, Gabbiani G, Brunner
HR, Burnier M: Blood pressure, cardiac, and renal responses to salt and deoxycorticosterone acetate in mice: role of Renin genes. J Am Soc Nephrol 2002, 13:1509-1516

21. Lum C, Shesely EG, Potter DL, Beierwaltes WH: Cardiovascular and renal phenotype in mice with one or two renin genes. Hypertension 2004, 43:79-86

22. Bowden DH: Unraveling pulmonary fibrosis: the bleomycin model. Lab Invest 1984, 50:487-488

23. Cavasin MA, Rhaleb NE, Yang XP, Carretero OA: Prolyl oligopeptidase is involved in release of the antifibrotic peptide Ac-SDKP. Hypertension 2004, 43:1140-1145

24. Ashcroft T, Simpson JM, Timbrell V: Simple method of estimating severity of pulmonary fibrosis on a numerical scale. J Clin Pathol $1988,41: 467-470$

25. Sur S, Wild JS, Choudhury BK, Sur N, Alam R, Klinman DM: Long term prevention of allergic lung inflammation in a mouse model of asthma by CpG oligodeoxynucleotides. J Immunol 1999, 162:6284-6293

26. Muggia FM, Louie AC, Sikic BI: Pulmonary toxicity of antitumor agents. Cancer Treat Rev 1983, 10:221-243

27. Lawson WE, Polosukhin VV, Stathopoulos GT, Zoia O, Han W, Lane KB, Li B, Donnelly EF, Holburn GE, Lewis KG, Collins RD, Hull WM, Glasser SW, Whitsett JA, Blackwell TS: Increased and prolonged pulmonary fibrosis in surfactant protein C-deficient mice following intratracheal bleomycin. Am J Pathol 2005, 167:1267-1277

28. Azizi M, Ezan E, Reny JL, Wdzieczak-Bakala J, Gerineau V, Menard $\mathrm{J}$ : Renal and metabolic clearance of $\mathrm{N}$-acetyl-seryl-aspartyl-lysylproline (AcSDKP) during angiotensin-converting enzyme inhibition in humans. Hypertension 1999, 33:879-886

29. Azizi M, Junot C, Ezan E, Menard J: Angiotensin I-converting enzyme and metabolism of the haematological peptide $\mathrm{N}$-acetylseryl-aspartyl-lysyl-proline. Clin Exp Pharmacol Physiol 2001, 28: 1066-1069

30. Molina-Molina M, Serrano-Mollar A, Bulbena O, Fernandez-Zabalegui L, Closa D, Marin-Arguedas A, Torrego A, Mullol J, Picado C, Xaubet A: Losartan attenuates bleomycin induced lung fibrosis by increasing prostaglandin $E_{2}$ synthesis. Thorax 2006, 61:604-610

31. Yang F, Yang XP, Liu YH, Xu J, Cingolani O, Rhaleb NE, Carretero OA: Ac-SDKP reverses inflammation and fibrosis in rats with heart failure after myocardial infarction. Hypertension 2004, 43:229-236

32. Shibuya K, Kanasaki K, Isono M, Sato H, Omata M, Sugimoto T, Araki S, Isshiki K, Kashiwagi A, Haneda M, Koya D: N-Acetyl-seryl-aspartyllysyl-proline prevents renal insufficiency and mesangial matrix expansion in diabetic db/db mice. Diabetes 2005, 54:838-845

33. Azizi M, Rousseau A, Ezan E, Guyene TT, Michelet S, Grognet JM, Lenfant M, Corvol P, Menard J: Acute angiotensin-converting enzyme inhibition increases the plasma level of the natural stem cell regulator $\mathrm{N}$-acetyl-seryl-aspartyl-lysyl-proline. J Clin Invest 1996, 97:839-844

34. Barelli H, Petit A, Hirsch E, Wilk S, De Nanteuil G, Morain P, Checler F: S 17092-1, a highly potent, specific and cell permeant inhibitor of human proline endopeptidase. Biochem Biophys Res Commun 1999, 257:657-661

35. Cavasin MA, Liao TD, Yang XP, Yang JJ, Carretero OA: Decreased endogenous levels of Ac-SDKP promote organ fibrosis. Hypertension 2007, 50:130-136

36. Zhuo JL, Carretero OA, Peng H, Li XC, Regoli D, Neugebauer W, Rhaleb NE: Characterization and localization of Ac-SDKP receptor binding sites using ${ }^{125}$-labeled Hpp-Aca-SDKP in rat cardiac fibroblasts. Am J Physiol Heart Circ Physiol 2007, 292:H984-H993

37. Kanasaki K, Koya D, Sugimoto $T$, Isono M, Kashiwagi A, Haneda $\mathrm{M}$ : N-Acetyl-seryl-aspartyl-lysyl-proline inhibits TGF- $\beta$-mediated plasminogen activator inhibitor-1 expression via inhibition of Smad pathway in human mesangial cells. J Am Soc Nephrol 2003, 14: 863-872 